\title{
Reasonableness of Limits, Reasonableness as Limit (in Legal Interpretation)
}

\author{
Maurizio Manzin ${ }^{1}$ (D)
}

Accepted: 14 December 2020 / Published online: 10 February 2021

(C) The Author(s) 2021

\begin{abstract}
This short essay aims at discussing the opposition between two different views on limits in legal interpretations: I will call them (i) "no-limits option" and (ii) "prolimits option". As for (i), it is based on a widely diffused understanding of individual freedom: that of an unceasing breaking of all limits. This idea involves nowadays not only a number of once accepted moral limits, nor the material or social limits suffered by people, but also the limits of conceptual determinations. As for (ii), it is based on the conjecture that limit would be the condition of "no longer, not yet"- -as such, a matter of authentic freedom. The "no-limits option" can easily lead, in legal interpretation, to a radical contextualism according to which there would be unlimited meanings for a syntactically and semantically same legal text. The "pro-limits option", on the contrary, maintains that the existence of limits is reasonable, and that reasonableness is itself a limit to interpretation. In other words, the undetermined space of "no longer, not yet" in which the limits consist of is open to exploration on and beyond through appropriate procedures of reason-giving. According to the "prolimits option", a reasonably common core-meaning of a legal text should be sought also when cases of application vary - and that would be precisely the nature of legal interpretation. Arguments in favor of this thesis can be found in Western philosophy from Aristotle to contemporary neurosciences (according to which reasonableness is natural). A remarkable consequence of my discussion on these two options deals with the concept of normativity, given that option (i) conceives normativity only as an expression of will (the one to establish and to infringe limits), whereas option (ii) links normativity to reasonableness.
\end{abstract}

Keywords Reasonableness $\cdot$ Legal interpretation $\cdot$ Limit $\cdot$ Normativity · Postmodernity

Maurizio Manzin

maurizio.manzin@unitn.it

1 Department of Law, University of Trento, Trento, Italy 


\section{A Previous Disambiguation}

It would be appropriate to distinguish in advance what this paper deals with and what it does not. ${ }^{1}$ First it does not deal with the so-called practical limits of law. A practical limit is generally intended as a limit concerning the relationship between the purpose of the legislature in making the rule - which involves the political level of the discussion, in the sense of the policies the law-makers agree with in order to regulate a certain social issue (as for instance the abuse of alcohol) and the means imagined to achieve this end, which can be known thanks to the text of the regulation (as for instance a general prohibition of alcohol consumption). In a case like this the limit is practical because the background reasoning is practical: more precisely, it is a practical syllogism the way Aristotle thought it to be (syllogismos ton prakton). It is famous his example in Book VI of Nicomachean Ethics (1141b1620) about health and the "wise" deduction of having light food like chicken meat in order to stay healthy (the premises: someone wants to be healthy, knows both that a good digestion is necessary to be healthy and that meat like the chicken one is light for digestion; the conclusion: therefore she decides to have chicken meat). The question of practical limits is typical in teleological accounts of law and more generally in utilitarian theories as well as, under certain respects, in legal realism and sociology of law. To remain at my example above, it should be considered if a general prohibition of alcohol consumption like the one operated by US government in the 1920s could actually be effective in limiting alcohol abuse or, on the contrary, it will end up encouraging it in illegal and hidden ways (just as it happened). The evaluation about limits like the means-ends ones is generally carried out a posteriori or at least it is grounded in advance (when the rule has to be established) on some experiences already made in the field or in similar fields - so that an a posteriori judgement is however required. This kind of limits is therefore a matter of "wisdom" (phronesis) and as such it implies reasonableness. That is exactly why I prefer to deal directly with reasonableness rather than discuss on one or the other of the practical limits of law.

Secondly my paper does not deal with the so-called principled limits of law. A principled limit is generally intended as a limit regarding the moral acceptability of rules. A discussion on such limits presupposes at least a meta-ethical choice about (i) the way the is-ought problem has to be addressed, and (ii) the set of moral values that has to be optioned to regulate the law-making, once it has been decided in favor of a connection between law and moral. A typical principled limit of law is the one regarding the coercion a state is authorized to exercise in order to maintain the safety and integrity of citizens and their property. It is clear that a problem like that should be addressed through a serious and rigorous reflection upon the moral commitment of a state within its constitutional frame. But whatever the reflection - here it is my point - it should anyhow be a reasonable one. Nobody would in fact like to admit that a moral claim is something irrational, a kind of emotional feeling or

\footnotetext{
${ }^{1}$ I rely on J. Stanton-Ife's qualification of the limits of law [16].
} 
impulse needing no argument to be maintained and justified. The same plurality of moral criteria we could choose from in a globalized world let us think that a reasonable justification of our choice, whatever it could be, is required. So at the end of the day the question of limits recalls the question of reasonableness, in legal discourses no less than in others, with the remarkable difference that in the history of legal philosophy the conjunction between practical reason and law is structural: reasonableness should actually be regarded as the proper nature of law, as stressed by the wellknown Cicero's maxim “est quidem vera lex recta ratio" (Rep 3,6) and famously set by the Digest (1.1.1).

It is just for this reason that my paper will avoid to focus on both practical and principled limits of law, rather preferring to challenge what I consider the main and inescapable question that has to be raised: that of the tension between reasonableness and limits.

I am thus taking into account in the following lines some issues implicated by this question. The first one entails some historical antecedents of the idea, typical of the postmodern condition, according to which the individual will cannot be limited by anything: precisely in this sense and to its extent it should be considered free (Sect. 2); the second one addresses the relationship between liberty and the limits in favor of a mutual implication of both (Sect. 3); the third one concerns more intimately legal semiotics, being a reflection on the logical or conceptual limits of legal discourses (Sect. 4); the last one briefly discusses the limits of normativity (Sect. 5). It will of course be only a provisional account on a very complex issue. Moreover I will consider here only the specific part of legal discourses represented by legal argumentation in judicial decisions (either from the part of the judge or from that of the lawyers), slightly addressing the role of reasonableness in being as well as in giving limits to law, just as the title of my essay suggests.

\section{The No-Limits Option}

\subsection{Some Antecedents}

I think it appropriate to introduce what I call "No-Limits Option" (hereinafter "NLO"), which I will illustrate shortly, by resorting to some paradigmatic examples in the history of legal philosophy. The first one is the famous assertion attributed to Thrasymachus (fifth century BC) and reported in Plato's Republic (1.338 c) according to that "justice is the advantage of the stronger". It seems quite clear that to Thrasymachus - no matter if the point is simply related or if it were personally approved by him - law can or could be reduced to the exercise of coercion [14] in favor of the one who has the power (an opinion that had vividly been expressed by Hesiod three centuries before in his poem on the Hawk and the Nightingale narrated in Works and Days). In this sense, contrary to the later opinion of Plato, law would have no limits but the ones established by the will.

Moving away from the ancient era, another authoritative example of NLO could be found in Sir T. Hobbes' notion of "right to everything" (ius in omnia) in his Leviathan - a right that would belong to each individual in a fictitious "state of nature". 
In the case of Hobbes too we are faced with a representation of law as an unlimited exercise of power, which shifted from the individuals' alleged "natural" state to the well concrete sovereign-state of the Leviathan.

Neither in Thrasymachus (and Hesiod) nor in Hobbes reasonableness is supposed to play as a limit to law: for both the stage is all for the will, intended as the entitlement to get what you want, if you have strength enough to do so.

It is important to notice that in modern as well as in contemporary times this kind of entitlement has been crucial in defining freedom: a definition largely inspired by a physical account to which limits (quiet) are the opposite of freedom (motion), in line with the anthropology of homo faber. Put in these terms, the account on freedom has become the problem of modern political and legal theories, given that the supremacy of will raises the question of establishing to what extent an individual's will should be limited by another's. So one way or another the question of limits appears to be unavoidable.

The point of arrival of NLO theories, which represents also the explosion of the modern aporia on liberty and power, is perfectly embodied by F. Nietzsche's "will of power" with its unambiguous claim to overcoming all limits, included reasonableness itself (and truth with it). This point has remarkable consequences for my discourse on the limits of law, particularly from the perspective of legal interpretation. According to a frequently quoted phrase attributed to Nietzsche, "there are no facts, only interpretations" (WP 481, 1, 11, 13; 540, 616). It is clearly about the so-called "perspectivism" and the idea that - once again Nietzsche - "there is no truth" and that "the character of existence is false", meaning that every kind of individual's expression, and therefore also the content of a rule, can be interpreted in many ways none of which is true. A skeptical attitude that in Nietzschean terms deals with both reality (world) and speeches, since they are always matter of individual will. To Nietzsche reality (world) is "in flux, incomprehensible, elusive" (WP 604): in other words, it is undetermined and indeterminable - conceptually limitless. That's why Nietzsche is considered the starting point of postmodernism and more in general of all philosophical accounts as well as simple common opinions affirming or implying that truth sets limits to will and thus to individual freedom.

I do not pretend that what I am arguing - truth as a limit to freedom - necessarily corresponds to a smoking gun pointed at a well-structured theory on (or to say better against) truth. Although for some cases one could actually think so (let us cite for instance the so-called semantic theories, like the deflationary or disquotational ones), what matters for my discussion is minimally the fact that even just with the tools of sociology one could easily observe a socially widespread attitude in favor of individuals' free expression whatever it may be, and contrary to every form of dogmatism.

\subsection{The Postmodern Condition}

If we look at F. Lyotard's criticism of the so-called "grand narratives" [7] (like the ones given over the centuries by myths, religion and science) or at Z. Bauman's concept of "liquidity" of contemporary globalized society [2], we could easily discover 
the tracks of the above cited Nietzschean idea of no-limits interpretation. And if the epistemological côté of such idea corresponds to interpretivism and antirealistic theories, the legal one is easily recognizable in rule skepticism and creative jurisprudence, as well as in some contemporary legal phenomena like legal pluralism, fragmentation of human rights and others. Many of these seem to indicate that liberty is mostly experienced as the goal of a (unending?) race towards the infringing of every, even conceptual limit to individuals' desires. ${ }^{2}$

The question is: is it reasonable to say that there is no truth and the space is open to any kind of interpretations? [3] My answer is quite trivial: in the real world and in standard conditions we can understand Nietzsche's claim on falsehood, and he himself wrote something he supposed to be reasonably true for us the readers. In other words, when we interact we do so within a condition of underlying rationality in which we communicate to each other referring to something (either to describe or to prescribe) we assume as existing (real) in a possible world. Utterances like $<$ Snow White has seven dwarfs for friends $>,<$ Murder is prohibited by \# 575 of Italian Penal Code $>,<$ Whales are mammals $>$ in the real world and in standard conditions are commonly intended as reasonable and true in their own possible worlds: respectively the one of fairy tales, law and natural Science. These worlds do have limits that prevent us from believing that Snow White is a fish, murder is allowed or whales have dwarfs for friends. It could of course be reasonable for whales to have dwarfs for friends - but in another and not yet written fairy tale; or for a fish in a bowl to be named Snow White by my little daughter - but not in the famous Disney's cartoon. More difficultly would murder be considered an allowed practice, although from time to time - in some awful possible worlds - this kind of distortion of reasonableness unfortunately happens.

Thus my point is that reasonableness and limits are inevitably connected, since they form the basis of communication between individuals, notwithstanding the postmodern widespread suspicion against every form of boundary. ${ }^{3}$

\section{The Pro-Limits Option}

After having sketched the negative attitude towards limits that usually supports NLO theories, in this section I will try to justify a positive account on the role of limits in their relation with freedom and reasonableness. I call this account "Pro-Limits Option" (hereinafter "PLO"). In order to argument on that I am previously providing a definition of limit, then I will discuss the "limits of liberty", and lastly I will consider two different kinds of relationship between limits and reasonableness.

\footnotetext{
2 Some further reflections upon fragmentation in postmodern condition can be found here: [10].

3 In this sense my view is pretty close to C.S. Peirce's opinion about truth as a "limit concept" [6].
} 


\subsection{Towards A Definition of Limit}

To the extent that the postmodern condition can be interpreted less as a truly new phase than as a late-modernity emphasizing subjectivity as individuality, various tendencies have been developed aiming at removing limits to will and desires, in the field of law as well as in others (incidentally this is also the reason why the tension between technoscience and law has become structural in contemporary society). I think however that the idea of limit should not be reproached or rejected without further reflection, in order to escape a superficial Manicheism on freedom as good and limits as bad.

I will give a trivial example about the function of limits inspired by the Italian national flag (by mere coincidence I am writing on the national Day of The Republic). As established by \# 12 of the Italian Constitution, "the flag of the Republic is the Italian tricolour: green, white and red, in three vertical bands of equal size". Not surprisingly, nothing is written about the limits between the green, white and red bands. Are these limits themselves green, white or red? Either green or white or red vertical band have of course their 'beginning' and their 'end', but nothing seems to stay in the middle. There are no borders or dividing lines colored some way; we can see only three vertical bands respectively green, white and red. All we can say is that 'at a certain point' (an invisible one) a particular identity or sameness (say, green) gives way to another (say, white) and, therefore, this point should be considered the limit between the two. The fact is that we cannot decide if such limit belongs to the green band or to the white. So what way does that limit exist?

My suggestion is of course that it exists as a relation between the two. Limits, in other words, show the difference between identities (or samenesses) - a difference that does not deny, say, green's or white's proper identity, but on the contrary it necessarily helps to determine what is green instead of white and vice versa. It follows that limits in themselves are neither true nor false, in the sense that we cannot say that it is true that the limit is green and it is false that is white, and vice versa. A conclusion which could seem paradoxical if we did not take into consideration W. H. Auden's admonishment: "You get ideas you have to turn down - 'I'm sorry, no longer'; 'I'm sorry, not yet'” [1: 730] [1].

I believe that the famous British-American poet has perfectly caught the point, because it is exactly this condition of being 'no longer, not yet' that the limit consists of. In the example above (the Italian flag) the limit between the green and the white band is no longer green and not yet white: it properly (i) keeps in relationship one band with the other, and (ii) contributes to the determination of each. Determination implies indeed to set limits (from the Latin determino), to draw borders, to somehow close - just as our thinking does when it conceptualizes in order to understand things. In the end, no relationship (and no comprehension) without limitation. 


\subsection{Liberty and the Limits}

We owe to J. M. Buchanan's influential book on the "limits of liberty" [4] a contemporary revival of the Kantian idea about the necessary relationship between freedom and the limits. To Buchanan liberty intended as 'do what you want' (the supremacy of will) leads inevitably to anarchy and violence, while limits intended as mere acts of strength exercised by political authority deliver citizens to the Leviathan (and to its will). Buchanan's reflection is upon the space laying between these two opposites - the space of democracy. My proposal is more philosophical and deals with the above cited condition of 'no longer, not yet'. In Kantian terms, it entails the space open to exploration on and beyond the "boundary" (die Schranke), which by itself does not constitute a "limit" (die Grenze) in the sense of a stop. "Bounds or boundary includes the sense of something beyond the bound, so that both sides have a space, so to speak". ${ }^{4}$

The 'end' of something, which is also the imaginary line traced by the reason in order to define it, is thus the special space for free research: it closes as a Grenze just to open as a Schranke: and that's the way I see the mutual implication of liberty and limits.

The question at this point is about the role of reason: is the special space of free research on and beyond the limits also open to unreasonable procedures? If so, we should conclude that between the anarchy of meaninglessness (i.e. contradiction) and the Leviathan of dogmatism (i.e. tautology) there is no room for critical investigations - no room for logic. ${ }^{5}$

\subsection{Reasonableness of/as Limit}

Given that limits are intrinsic to determination and understanding, and that they are not the enemies of freedom, we can serenely conclude that free exploration on and beyond the limits does not constitute by itself a negation of rationality and logic. This becomes particularly crucial when exploration is finalized to a decision that must be taken in order to act, as in practical judgements [12]. Either in institutionalized (like the legal one) or non-institutionalized contexts (like the many ones of public debate) argument finalized to decision often grapples with vagueness of determinations, on and beyond the limits of definitions, opinions, beliefs etc. That is the case when, for instance, lawyers in front of a judge or a jury propose and defend a certain interpretation about norms or alleged facts. Their game along the borders is a matter of both liberty and reason (or to say better reasonableness, intended in the sense of phronesis: reason for practical use), in a double way.

On one side it is reasonable to maintain, as shown above, that limits (Kant's Schranken) do not prevent from freely taking a look beyond them - towards differences that help to better determine the sameness (or identity) of the issue at stake,

\footnotetext{
${ }^{4}$ Kant uses the term "limit" in a negative sense, and "boundary" in a positive one [3:35].

${ }^{5}$ It is just between contradiction and tautology that, according to Wittgenstein, logic plays its role (TLP 4.461-6, 6.124).
} 
in order to decide and act. On the other side reasonableness must be a limit just to avoid that freedom could be interpreted as an invite to anarchy-meaninglessness, which inevitably leads to its opposite: the Leviathan of the supremacy of will by the use of force - if not violence. That's why I assume that it is reasonable to have limits and that reasonableness is indeed a limit.

\section{Limits of Legal Interpretation}

In his criticism of Hart's notions of open texture and vagueness, F. Schauer claims that propositions of law often contain terms whose fringe area is prima facie not so problematic as for clearly vague terms like, for instance, 'tall'. He gives as an example the term 'wine' [13]:

"its extension is quite precise, such that the vast majority of substances, and even the vast majority of potable liquids, are easily classified as wine or not wine. But whether non-alcoholic wine is wine at all is not so clear. Consequently, we can say that non-alcoholic wine is located in the relatively small fringe of a term with a large core of settled meaning - a term containing, overwhelmingly, clear cases of application or non-application" [13: 5 and 14: $38 \mathrm{ff}]$.

One could give a similar example, very sensitive for international law scholars, with the term 'war'. Is it applicable, in its common and "quite precise extension", in cases like the ones in which multilateral military missions are involved in the so-called "peace operations"? In missions like such the situation on the ground is under many respects very different from what is commonly known as war (to the point that it has been thought up the acronym "OTW": Other Than War operations). To Schauer the question entails legal interpretation, insofar as semantic limits in the propositions of law are not so evanescent as they are with vague terms (people are normally not uncertain about the meaning of terms like 'wine' or 'war') - when, in other words, limits are recognized as such. Only under particular conditions (nonalcoholic wines or undeclared armed conflicts) what the limits of these terms consist of becomes a matter of exploration on and beyond.

Let us turn back once again to my example of the Italian flag. Just as the Italian constitution, the Irish fundamental act establishes in \# 7 that " $[\mathrm{t}]$ he national flag is the tricolour of green, white and orange". Although in the Irish case the description/ prescription is less detailed than the Italian (reference to vertical and equal-sized bands is lacking), for people of the Republic of Ireland as well as for my people, the object designated by the term 'flag' in the Constitutional norm is no less known than the one of 'wine' for French or 'war' for US. Nevertheless in everyday life situations it occurs that, say, the difference between the red and orange vertical bands (a difference which solely distinguishes the two national flags, which are otherwise very similar) were not so clearly perceptible. I remember for instance an official visit of Irish authorities in Rome in which many flags - either Irish or Italian - waved by people around the presidential procession could not be clearly distinguished from each other because of the flags' wear, probably caused by exposure to bad weather: were they orange or red? 
What frequently happens in real life situations raises the question of limits, no matter if material or conceptual. What does the fringe between red and orange consist of, either in materially distinguishing some waved flags or in culturally distinguishing Celtic traditions from the Latin ones? The space is of course open for special exploration in the context on and beyond. To distinguish orange and red in both Irish and Italian flags might have no appreciable consequences in watching a state visit on TV, but it would probably have in diplomacy (let us imagine a conference at UN with the wrong flag).

It is up to reasonableness to detect the limit in different and specific contexts, and to evaluate what is evidently out of bounds in a diplomatic context but not so worrisome in a generic public situation. As far as legal reasoning is concerned interpretation $i s$ limited not only from a semantic point of view, but also by some structural (pragmatic) conditions regarding the judicial context. In effect, reasonable exploration on and beyond the limits of normative terms does not 'happens' in an empty space: conceptualization and space-time conditions are in many ways connected to each other. Trials have space and time strictly regulated by procedural norms, so that legal decisions are limited not only by cognitive elements (such as interpretative rules, legal doctrine, principles, binding precedents etc.) but also by institutional ones. The rules of the game in judicial contexts are dictated by a complex of factors like the adversary framework of the discussion, its seemingly non-cooperative nature [11], ${ }^{6}$ the fact of being argumentatively "trilogical" [5] (and therefore rhetorical), together with the above mentioned institutionalized and performative character of the judgement. All these elements have good reasons for having been provided, and they in turn imply reasonableness.

\section{Legal Normativity and the limits}

As I have long stayed in the previous sections on the relationship between limit, will, freedom and reasonableness I will be now extremely brief on this issue.

Normativity, as NLO accounts put it, is a matter of mere will: legal norms would be positive (also in the sense of formal) expressions of what the legislature or the judge decide that should be done. In this regard we could remember the famous Hobbes' claim according to which auctoritas non veritas facit legem (Lev 2. 26). So what could be the limits of will if not the ones established by the lawmaker itself? In constitutionalised systems the limits of both the legislature and the judge - on how and what they can decide - are of course outlined by the norms, insofar as they are inspired by the principle of the rule of law. But this principle necessarily implies reasonableness, to which it is strictly connected [9]. It follows that NLO accounts end right where the applicability of reasonableness begins.

On the contrary, PLO accounts maintain that the existence of limits is reasonable in itself and that reasonableness is itself a limit to what should be done. In these accounts normativity is based pro tanto on "reasons to act" [15] - reasons that in judicial contexts have notoriously to be exhibited through either "internal" or "external" justification [12: 147-174]. It follows that PLO theories based on

\footnotetext{
${ }^{6}$ On why non-cooperativity of judicial speeches were only apparent, see [8].
} 
reasonableness conceive normativity as inextricably linked to the argumentative work required by justification.

Work that in my view is overwhelmingly rhetorical.

Funding Open Access funding provided by Università degli Studi di Trento.

Open Access This article is licensed under a Creative Commons Attribution 4.0 International License, which permits use, sharing, adaptation, distribution and reproduction in any medium or format, as long as you give appropriate credit to the original author(s) and the source, provide a link to the Creative Commons licence, and indicate if changes were made. The images or other third party material in this article are included in the article's Creative Commons licence, unless indicated otherwise in a credit line to the material. If material is not included in the article's Creative Commons licence and your intended use is not permitted by statutory regulation or exceeds the permitted use, you will need to obtain permission directly from the copyright holder. To view a copy of this licence, visit http://creativecommons.org/licen ses/by/4.0/.

\section{References}

1. Auden, Wystan Hugh. 2010. The Complete Works of W.H. Auden: Prose vol 6: 1969-1973. Princeton University Press, Princeton

2. Bauman, Zygmunt. 2000. Liquid Modernity. Cambridge: Polity Press.

3. Bourgeois, Patrick. 2001. Philosophy at the Boundary of Reason: Ethics and Postmodernity. Albany: State University of New York Press.

4. Buchanan, James McGill. 1975 The Collected Work of James M. Buchanan vol 7: The Limits of Liberty: Between Anarchy and Leviathan. University of Chicago Press, Chicago

5. Kerbrat-Orecchioni, Caterina, and Plantin Christian. 1995. Le Trilogue. Lyon: Presses Universitaires de Lyon.

6. Legg, Catherine. 2014. Charles Peirce's Limit Concept of Truth. In Philosophy Compass 9(3): 204213. https://doi.org/10.1111/phc3.12114. Accessed 24 June 2020.

7. Lyotard, Jean François. 1984. The Postmodern Condition: A Report on Knowledge. Minneapolis: University of Minnesota Press.

8. Manzin, Maurizio. 2016. Is the Distinction Between "Cooperative" and "Strategic" Crucial for Jurisprudence and Argumentative Theory?. Argumentation and Reasoned Action. Proceedings of the 1st European Conference on Argumentation: 129-133. Milton Keynes: College Publications.

9. Manzin, Maurizio. 2016. Legal Argumentation Between 'Monologue' and 'Dialogue': From the Absolute Ruler to the Rule of Law. Legal Argumentation and the Rule of Law: 123-131. The Hague: Eleven International Publishing.

10. Manzin, Maurizio. 2019. In What Sense Are Human Rights Universal?. Metaphysics of Human Rights: 87-102. Vernon Press, Wilmington

11. Marmor, Andrei. 2014. The Language of Law. Oxford: Oxford University Press.

12. Redondo, Cristina. 1999. Reasons for Actions and the Law. Dordrecht: Springer.

13. Schauer, Frederick. 2011. On the Open Texture of Law. Defeasibility in Philosophy: Knowledge, Agency, Responsibility, and the Law: 197-215. Amsterdam: Editions Rodopi B.V.

14. Schauer, Frederick. 2015. The Force of Law. Cambridge: Harvard University Press.

15. Setiya, Kieran. 2014. What Is a Reason to Act? Philosophical Studies 167 (221-235): 2020. https:// doi.org/10.1007/s11098-012-0086-2.Accessed23June.

16. Stanton-Ife, John. 2006. The Limits of Law. The Stanford Encyclopedia of Philosophy (Winter 2016 Edition). https://plato.stanford.edu/archives/win2016/entries/law-limits/. Accessed 21 May 2020.

Publisher's Note Springer Nature remains neutral with regard to jurisdictional claims in published maps and institutional affiliations. 